\title{
Potencial antiproliferativo do óleo essencial de Origanum majorana Linn. em células de melanoma e seus efeitos intracelulares em células neoplásicas e não-neoplásicas
}

Antiproliferative potential of the essential oil of Origanum majorana Linn. in melanoma cells and intracellular effects on neoplastic and non-neoplastic cells

Potencial antiproliferativo del aceite esencial de Origanum majorana Linn. en células de melanoma y sus efectos intracelulares en células neoplásicas y no neoplásicas

Cristine Cioato da Silva ORCID: https://orcid.org/0000-0002-6494-4049 Universidade Federal de Pelotas, Brasil E-mail: criscioato@hotmail.com Claudia Giordani ORCID: https://orcid.org/0000-0003-2368-5471 Universidade de Caxias do Sul, Brasil E-mail: claarte@ hotmail.com Tony Picoli ORCID: https://orcid.org/0000-0002-4806-4973 Universidade Federal de Pelotas, Brasil E-mail: tony_picoli@yahoo.com.br

Karina Affeldt Guterres ORCID: https://orcid.org/0000-0001-9762-8117 Universidade de Caxias do Sul, Brasil E-mail: guterres.karina@gmail.com Soliane Carra Perera ORCID: https://orcid.org/0000-0002-9953-7558 Centro Universitário IDEAU, Brasil E-mail: soliane.cp@gmail.com

Gabriela Almeida Capella ORCID: https://orcid.org/0000-0002-3818-4613 Universidade Federal de Pelotas, Brasil

E-mail: gabicapella@gmail.com

Stefanie Bressan Waller ORCID: https://orcid.org/0000-0001-6719-1794 Universidade Federal de Pelotas, Brasil E-mail: waller.stefanie@yahoo.com.br

Carine Dahl Corcini

ORCID: https://orcid.org/0000-0001-5683-7801 Universidade Federal de Pelotas, Brasil

E-mail: corcinicd@gmail.com Antônio Sergio Varela Junior

ORCID: https://orcid.org/0000-0003-4901-5118 Universidade Federal de Pelotas, Brasil

E-mail: varelajras@hotmail.com

Rogério Antônio Freitag

ORCID: https://orcid.org/0000-0003-3714-2080 Universidade Federal de Pelotas, Brasil E-mail: rafreitag@gmail.com

Geferson Fischer

ORCID: https://orcid.org/0000-0002-3521-395X Universidade Federal de Pelotas, Brasil E-mail: geferson.fischer@gmail.com

Marlete Brum Cleff

ORCID: https://orcid.org/0000-0001-9082-5185 Universidade Federal de Pelotas, Brasil

E-mail: marletecleff@gmail.com

\section{Resumo}

Os objetivos desse estudo foram avaliar a atividade intracelular do óleo essencial de Origanum majorana (MARJ) nas linhagens Madin Darby Bovine Kidney (MDBK) e de melanoma metastático murino (B16F10) e elucidar a sua 
composição química. Através da citometria de fluxo foram analisados os parâmetros fluidez de membrana (F), espécies reativas de oxigênio (ERO), índice de fragmentação de DNA (IFD), potencial de membrana mitocondrial (PMM), ciclo celular, lipoperoxidação da membrana plasmática (LPO), viabilidade celular, necrose e apoptose das linhagens celulares tratadas com MARJ nas concentrações de 0,25, 0,5 e $1 \mathrm{mg} / \mathrm{mL}$ por 24 horas. A composição do MARJ foi determinada através de cromatografia gasosa, sendo seus componentes majoritários os terpenos: cissabineno hidratado, 4-terpineol e gama-terpineno. Os resultados mostraram que todas as concentrações de MARJ reduziram ERO, LPO e as células em fase S da linhagem MDBK. Nas células B16F10, os tratamentos com MARJ reduziram ERO e as células em fase G2, aumentando as células na fase $\mathrm{S}$. As concentrações de 0,5 e $1 \mathrm{mg} / \mathrm{mL}$ causaram redução na $\mathrm{F}$ e $0,5 \mathrm{mg} / \mathrm{mL}$ aumentou o PMM na linhagem MDBK, enquanto LPO foi reduzida na concentração de $0,5 \mathrm{mg} / \mathrm{mL}$ nas células B16F10. Os resultados das avaliações da produção de ERO, da integridade da membrana plasmática e de LPO indicaram atividade antioxidante nas linhagens estudadas. Através da análise do ciclo celular foi possível observar que MARJ exerceu efeito antiproliferativo sobre as células de melanoma, sendo capaz de interromper a multiplicação desse tipo celular.

Palavras-chave: Citometria de fluxo; Câncer; Citotoxicidade; Melanoma; Manjerona.

\begin{abstract}
The objectives of this study were to evaluate the intracellular activity of the essential oil of Origanum majorana (MARJ) in Madin Darby Bovine Kidney (MDBK) and murine metastatic melanoma (B16F10) and elucidate your chemical composition. Through flow cytometry parameters were analyzed membrane fluidity (F), reactive oxygen species (ROS), DNA fragmentation index (IFD), mitochondrial membrane potential (MMP), cell cycle, plasma membrane lipoperoxidation (LPO), cell viability, necrosis and apoptosis of cell lines treated with MARJ at concentrations of $0.25,0.5$ and $1 \mathrm{mg} / \mathrm{mL}$ for 24 hours. The composition of MARJ was determined by gas chromatography, and its major components were terpenes: hydrated cis-sabinene, 4-terpineol and gamma-terpinene. The results showed that all MARJ concentrations reduced ROS, LPO and S phase cells of the MDBK lineage. In B16F10 cells, MARJ treatments reduced ROS and cells in G2 phase, increasing cells in S phase. Concentrations of 0.5 and $1 \mathrm{mg} / \mathrm{mL}$ caused a reduction in $\mathrm{F}$ and $0.5 \mathrm{mg} / \mathrm{mL}$ increased the MMP in the MDBK lineage, while LPO was reduced at the concentration of $0.5 \mathrm{mg} / \mathrm{mL}$ in the B16F10 cells. The results of the evaluations of ROS production, plasma membrane integrity and LPO indicated antioxidant activity in the cells studied. Through cell cycle analysis, it was possible to observe that MARJ exerted an antiproliferative effect on melanoma cells, being able to interrupt the multiplication of this cell type.
\end{abstract}

Keywords: Flow cytometry; Cancer; Cytotoxicity; Melanoma; Marjoram.

\title{
Resumen
}

Los objetivos de este estudio fueron evaluar la actividad intracelular del aceite esencial de Origanum majorana (MARJ) en linajes de Madin Darby Bovine Kidney (MDBK) y melanoma metastásico murino (B16F10) y dilucidar su composición química. Mediante citometría de flujo se analizaron parámetros de fluidez de membrana (F), especies reactivas de oxígeno (ERO), índice de fragmentación del ADN (IFA), potencial de membrana mitocondrial (PMM), ciclo celular, lipoperoxidación de la membrana plasmática (LPO), viabilidad celular, necrosis y apoptosis de linajes celulares tratadas con MARJ a concentraciones de 0,25, 0,5 y $1 \mathrm{mg} / \mathrm{mL}$ durante 24 horas. La composición de MARJ se determinó por cromatografía de gases, y sus componentes principales fueron terpenos: cis-sabineno hidratado, 4terpineol y gamma-terpineno. Los resultados mostraron que todas las concentraciones de MARJ redujeron ERO, LPO y células de fase $\mathrm{S}$ del linaje MDBK. En las células B16F10, los tratamientos MARJ redujeron ERO y células en fase $\mathrm{G} 2$, aumentando las células en fase $\mathrm{S}$. Concentraciones de 0.5 y $1 \mathrm{mg} / \mathrm{mL}$ provocaron una reducción en $\mathrm{F}$ y 0.5 $\mathrm{mg} / \mathrm{mL}$ aumentaron las PMM en el linaje MDBK, mientras que la LPO se redujo a la concentración de $0,5 \mathrm{mg} / \mathrm{mL}$ en las células B16F10. Los resultados de las evaluaciones de producción de ERO, integridad de la membrana plasmática y LPO indicaron actividad antioxidante en las células estudiadas. A través del análisis del ciclo celular, se pudo observar que MARJ ejercía un efecto antiproliferativo sobre las células del melanoma, pudiendo interrumpir la multiplicación de este tipo celular.

Palabras clave: Citometría de flujo; Cáncer; Citotoxicidad; Melanoma; Mejorana.

\section{Introdução}

O câncer é considerado um problema de saúde pública global, sendo a segunda principal causa de morte em humanos, perdendo apenas para as enfermidades cardiovasculares (Fitzmaurice et al., 2016). No ano de 2020, o Brasil registrou mais de 626 mil novos casos de câncer em humanos (INCA, 2021). Em nível mundial, o câncer de pele é o mais diagnosticado, sendo o carcinoma basocelular o tipo mais frequente (Bray et al., 2018). O melanoma, apesar não ser a mais incidente, é a neoplasia com maiores taxas de formação de metástase e de mortalidade (American Cancer Society, 2021).

Melanomas são neoplasmas malignos formados a partir de melanócitos e melanoblastos, que são células produtoras de 
melanina (Goldschmidt \& Hendrick, 2002). Em animais domésticos, os cães são a espécie mais comumente afetada, ao contrário dos gatos, que raramente apresentam esse tipo de neoplasia (Weyden et al., 2020). Em cães, os melanomas cutâneos são os mais frequentes, assim como em humanos, mas essa neoplasia pode ocorrer primariamente também em mucosas, leito subungueal, globo ocular, trato gastrintestinal e sistema nervoso central (Silva et al., 2017; Weyden et al., 2020).

Por tratar-se de uma doença de prognóstico desfavorável e com resposta terapêutica limitada, principalmente em medicina veterinária, o câncer vem despertando o interesse científico para a busca de novas formulações medicamentosas que sejam atuantes em alvos tumorais específicos, reduzindo os efeitos colaterais e adversos da terapia, além de superar os mecanismos de resistência desenvolvidos pelas células neoplásicas, ou ainda, que apresentem propriedades preventivas à formação de neoplasias (Khan et al, 2014; Fitzmaurice et al., 2016).

Como estratégia de busca de novas fontes terapêuticas, estudos com plantas medicinais têm destacado o potencial antineoplásico de Origanum majorana Linn. (Lamiaceae), popularmente conhecida por manjerona. Extratos dessa planta já demonstraram capacidade em impedir a progressão tumoral, inibindo a formação de metástases e a proliferação celular maligna em células neoplásicas cerebrais (Dhaheri et al., 2014), estomacais (Balusamy et al., 2018) e de melanoma (Silva, 2016), além de apresentar baixa toxicidade para células não neoplásicas (Dhaheri et al., 2013; Silva, 2016; Balusamy et al., 2018). Além disso, essa planta apresenta ainda potencial para prevenção do câncer, graças às propriedades antioxidantes e antiinflamatórias (El-Ashmawy et al., 2007; Ramadan et al., 2012; Habibi et al., 2014).

O mecanismo de ação dessa planta pode variar em função do método de extração de seus componentes e pode envolver a expressão ou supressão gênica, as vias de sinalização do ciclo celular, apoptose e diferenciação celular (Tatman \& Mo, 2002). Porém, apesar de ter seus efeitos antitumorais reconhecidos, ainda há poucos estudos que elucidem o mecanismo de ação do Origanum majorana em células de melanoma.

Dessa forma, o presente estudo teve como objetivos a avaliação dos efeitos intracelulares do óleo essencial de Origanum majorana Linn. em uma linhagem celular neoplásica de melanoma metastático murino (B16F10) e em uma nãoneoplásica, de rim bovino (MDBK) e determinar a sua composição química.

\section{Materiais e Métodos}

\subsection{Tipo de Pesquisa}

O presente trabalho se trata de uma pesquisa experimental de abordagem quantitativa (Pereira et al., 2018) para fins de avaliação dos efeitos intracelulares do referido óleo essencial da planta sobre as células neoplásicas e não-neoplásicas, além de sua caracterização química.

\subsection{Obtenção do material vegetal e extração do óleo essencial}

As folhas secas de O. majorana Linn. foram adquiridas de distribuidor comercial. Para a extração do óleo essencial, foi realizada a extração com arraste de vapor, em aparelho Clevenger, durante 4 horas (Brasil, 1988). Após a extração, o óleo essencial foi submetido à secagem com sulfato de sódio anidro (Na2SO4, p.a.), concentrado em nitrogênio $\left(\mathrm{N}_{2}, 99.99 \%\right.$ w/v, White Martins) e armazenado em frasco âmbar, sob refrigeração.

\subsection{Determinação da composição química do óleo essencial de $O$. majorana}

Para a identificação dos compostos químicos do óleo essencial foi utilizado cromatógrafo a gás acoplado a detector de massas (GC/MS-QP 2010SE-Shimadzu, Japão), equipado com auto injetor AOC-20i. As quantificações foram feitas por área normatizada e as identificações dos compostos pelo espectrômetro de massas, utilizando a biblioteca NIST 8 do GC/MS. 


\subsection{Preparo e tratamentos dos cultivos celulares}

Os efeitos intracelulares foram avaliados em linhagens celulares de rim bovino (Madin Darby Bovine Kidney MDBK) e de melanoma murino (linhagem B16F10) crescidas em meio essencial mínimo de Eagle (E-MEM, SigmaAldrich $®$ ), conforme metodologia prévia (Waller et al., 2019). O meio E-MEM foi suplementado com soro fetal bovino a $10 \%$ (SFB), penicilina (Sigma-Aldrich $\left.{ }^{\circledR}\right)$, estreptomicina (Vetec $\left.®\right)$, enrofloxacina (Bayer®) e anfotericina B (Cristáliaß), com pH 7,2 e mantido em estufa com atmosfera úmida com $\mathrm{CO}_{2}$ a $5 \%$, a $37^{\circ} \mathrm{C}$ de temperatura.

As células em fase exponencial de crescimento foram então diluídas em E-MEM, suplementado com $10 \%$ de SFB até alcançar a concentração de $3 \times 10^{4}$ células $/ \mathrm{mL}$. Alíquotas da suspensão $(100 \mu \mathrm{L})$ foram transferidas para poços individuais de microplacas, e incubadas em estufa com meio E-MEM com 5\% de $\mathrm{CO} 2$ a $37^{\circ} \mathrm{C}$. Após 24 horas de incubação, as células foram tratadas com o óleo essencial de O. majorana (MARJ) nas concentrações de $0,25 \mathrm{mg} / \mathrm{mL}, 0,5 \mathrm{mg} / \mathrm{mL}$ e $1 \mathrm{mg} / \mathrm{mL}$, em triplicata, por 24 horas, e incubadas em atmosfera úmida com $5 \% \mathrm{CO}_{2}$ por 24 horas a $37^{\circ} \mathrm{C}$ (exceto as células utilizadas para determinação de LPO, que, de acordo com a metodologia específica, receberam os tratamentos, conforme descrito no item 2.5.5). Transcorridas 24 horas de incubação, as suspensões de células referentes a cada tratamento foram transferidas para um tubo cônico (Eppendorf®) e procedeu-se de acordo com a metodologia indicada para cada leitura realizada na citometria de fluxo.

\subsection{Citometria de fluxo das linhagens celulares B16F10 e MDBK}

Potencial de membrana mitocondrial (PMM), apoptose, necrose, espécies reativas de oxigênio (ERO), ciclo celular, índice de fragmentação de DNA (IFD), fluidez de membrana (F) e lipoperoxidação (LPO) foram os parâmetros avaliados através de citometria de fluxo (Attune ${ }^{\circledR}$ Acoustic Focusing - Life Tecnologies), utilizando o programa Attune Cytometric Software v 2.1.

Para a análise, as populações celulares foram avaliadas pelo fotodetector VL1 (filtro 450/40), e as células receberam Hoechst 33342 para todas as análises. As fluorescências de H2DCFDA (para avaliação das ERO) e rodamina 123 (funcionalidade de mitocôndrias - PMM) foram lidas através do fotodetector BL1 (filtro 530/30). A fluorescência de iodeto de propídeo (para as avaliações de necrose, fragmentação de DNA e ciclo celular) foi lida através do fotodetector BL3 (filtro 640LP). Dez mil eventos foram analisados por amostra com fluxo de 50 células/segundos. Debris celulares e células agrupadas foram eliminados baseando-se em gráficos de dispersão (Petrunkina et al., 2013).

\subsubsection{Potencial de membrana mitocondrial (PMM)}

O potencial de membrana mitocondrial foi avaliado usando rodamina 123. Após serem incubadas com as três concentrações do óleo essencial, as células foram lavadas duas vezes com tampão fosfato salino (PBS) e incubadas com EMEM e $150 \mu \mathrm{L}$ de rodamine 123 durante 60 minutos. Em seguida, foram adicionados $300 \mu \mathrm{L}$ de Hoechst 33342 por 30 minutos e realizada a leitura. A intensidade da rodamina 123 está diretamente relacionada ao potencial da membrana mitocondrial, pois ela se concentra nas mitocôndrias mais ativas (Sharma et al., 2010).

\subsubsection{Necrose e apoptose}

Após 24 horas de incubação com as três concentrações de MARJ, as células foram lavadas duas vezes com PBS e foram acrescidos $0,2 \mu \mathrm{L}$ de Annexin $\mathrm{V}$ conjugado com isotiocianato de fluoresceína (FITC), sendo as placas incubadas por 60 minutos a $37^{\circ} \mathrm{C}$. Em seguida, foram acrescentados $80 \mu \mathrm{L}$ de MEM e $2 \mu \mathrm{L}$ de iodeto de propídeo (IP), sendo novamente incubadas por 30 minutos. Posteriormente, foi removido o sobrenadante e as placas foram novamente incubadas por 5 minutos com paraformaldeído e em seguida acondicionadas em gelo até a leitura (Abdel-Massih et al., 2010). As células normais e 
viáveis não apresentam marcação (FITC -, IP -); as células apoptóticas externalizam a fosfatidilserina que é reconhecida pelo Anexin V (FITC +, IP-); células necróticas são reconhecidas por ter a membrana nuclear rompida e IP ligado ao material genético (FITC-, IP+ e FITC+, IP+).

\subsubsection{Espécies reativas de oxigênio (ERO)}

Após a incubação das células com o MARJ por 22 horas, foram acrescidos $2 \mu \mathrm{L}$ de H2DCF-DA e novamente incubados por 90 minutos. Posteriormente, foram adicionados $4 \mu \mathrm{L}$ de iodeto de propídeo, incubados por 20 minutos e então acrescidos $2 \mu \mathrm{L}$ de H33342. Após 10 minutos foi então realizada a leitura (Domínguez-Rebolledo et al., 2010). Os resultados obtidos nesta avaliação são expressos em intensidade de luminosidade.

\subsubsection{Ciclo celular}

Após os tratamentos, as células foram lavadas duas vezes com PBS e ressuspensas em $1 \mathrm{~mL}$ de solução hipotônica gelada contendo $0,1 \%$ de triton X-100, $0,1 \%$ de tampão de citrato e $0,1 \mathrm{mg} / \mathrm{mL}$ de RNAse e $50 \mu \mathrm{g} / \mathrm{mL}$ de iodeto de propídeo e incubadas durante 15 minutos a $37^{\circ} \mathrm{C}$, protegidas da luz. Após a incubação, a suspensão celular foi analisada quanto às proporções relativas de células na fase G0-G1, fase S e fase G2/M (Arathi et al., 2016).

\subsubsection{Lipoperoxidação (LPO)}

As células foram incubadas por 4 horas com $1 \mu \mathrm{L}$ de C11-BODIPY, antes da adição do óleo essencial. Após esse período, foram acrescidas as três concentrações de óleo essencial de manjerona e as células foram incubadas por 24 horas antes da leitura sendo os resultados expressos através da média das fluorescências verde (presença de lipoperoxidação) e vermelha (ausência de lipoperoxidação), considerada a porcentagem de presença de LPO (Silva et al., 2012).

\subsection{6 Índice de fragmentação do DNA (IFD)}

Para a avaliação do DNA, após a incubação das células com os tratamentos por 24 horas, foram adicionados $150 \mu \mathrm{L}$ de tampão TNE (0,01 M Tris-HCl, 0,15 M NaCl, 0,001 M EDTA, pH 7,2) por 30 segundos, posteriormente $300 \mu \mathrm{L}$ de Triton $(0,1 \%$ Triton X-100) por 30 segundos, e $150 \mu \mathrm{L}$ de acridine laranja (ácido cítrico 0,037 M, Na2HPO4 0,126 M, 0,0011 M de EDTA dissódico, $\mathrm{NaCl}$ 0,15 M, pH 6,0) por 2 minutos (Evenson \& Jost, 1994). As leituras foram realizadas em até 2 minutos após a adição do corante, e os resultados expressos em índice de DNA fragmentado.

\subsection{Análise estatística}

As análises estatísticas foram feitas pelo software Statistix versão 10.0®, utilizando a análise de variância (ANOVA) para comparação entre os tratamentos. As médias foram comparadas pelo teste de Tukey, sendo considerados resultados significativos quando $p<0,05$.

\section{Resultados e Discussão}

O óleo essencial utilizado nesse estudo apresentou os terpenos como constituintes majoritários, sendo o cis-sabineno hidratado, o 4-terpineol e o gama-terpineno, os predominantes (Figura 1). Esses compostos são reconhecidos por suas propriedades antioxidantes (Del Ré \& Jorge, 2012). Além disso, deve-se considerar ainda o sinergismo existente entre os componentes de um óleo essencial, o que pode potencializar as suas propriedades terapêuticas (Hajlaoui et al., 2016; Nanni et al., 2020). 
Figura 1 - Cromatograma do óleo essencial de manjerona Os picos enumerados correspondem aos compostos químicos (tempo de retenção; área): 1 - não identificado (5,92 min.; 0,35\%); 2 - $\alpha$-thujene $(6,36$ min.; 1,6\%), 3 - $\alpha$-pinene $(6,53$ min.; 0,61\%), 4 - $\alpha$ phelandrene (7,59 min.; 7,52\%), 5 - $\beta$-pinene (8,06 min.; 1,43\%), 6 - $\alpha$-terpinene $(8,77$ min.; $6,13 \%), 7$ - $\rho$ cymene (pico 7), 8 - $\beta$-phelandrene $(9,10$ min.; 2,97\%), 9 - $\gamma$-terpinene $(9,98$ min.; 8,90\%), 10 - trans-sabinenehydrate (10,22min.;6,40\%), 11 - $\delta$-2-carene (10,81 min,; 2,01\%), 12 - cis-sabinene hydrate (11,16 min.; 22,20\%), 13 - não identificado (11,77 min.; 2,09\%), 14 - não identificado (12,29 min.; 1,33\%), 15 - terpinen-4-ol (13,44 min.; 14,10\%),16 - $\alpha$-terpineol (13,79 min.; 3,86\%), 17 - não identificado (14,25 min.; 0,67\%), 18 - não identificado (15,54 min.; 9,90\%), 19 - linalool acetate (15,57 min.; 1,92\%), 20 - 4-terpinenyl acetate (16,81 min.; 0,93\%), 21 - caryophyllene (19,99 min.; 2,43\%), 22 - elixene (21,92 min.; 1,47\%), 23 - spathulenol (23,86 min.; 0,30\%), 24 - não identificado (24,0 min.; 0,17\%). Destacam-se os picos 12, 15 e 9 que correspondem aos compostos majoritários identificados.

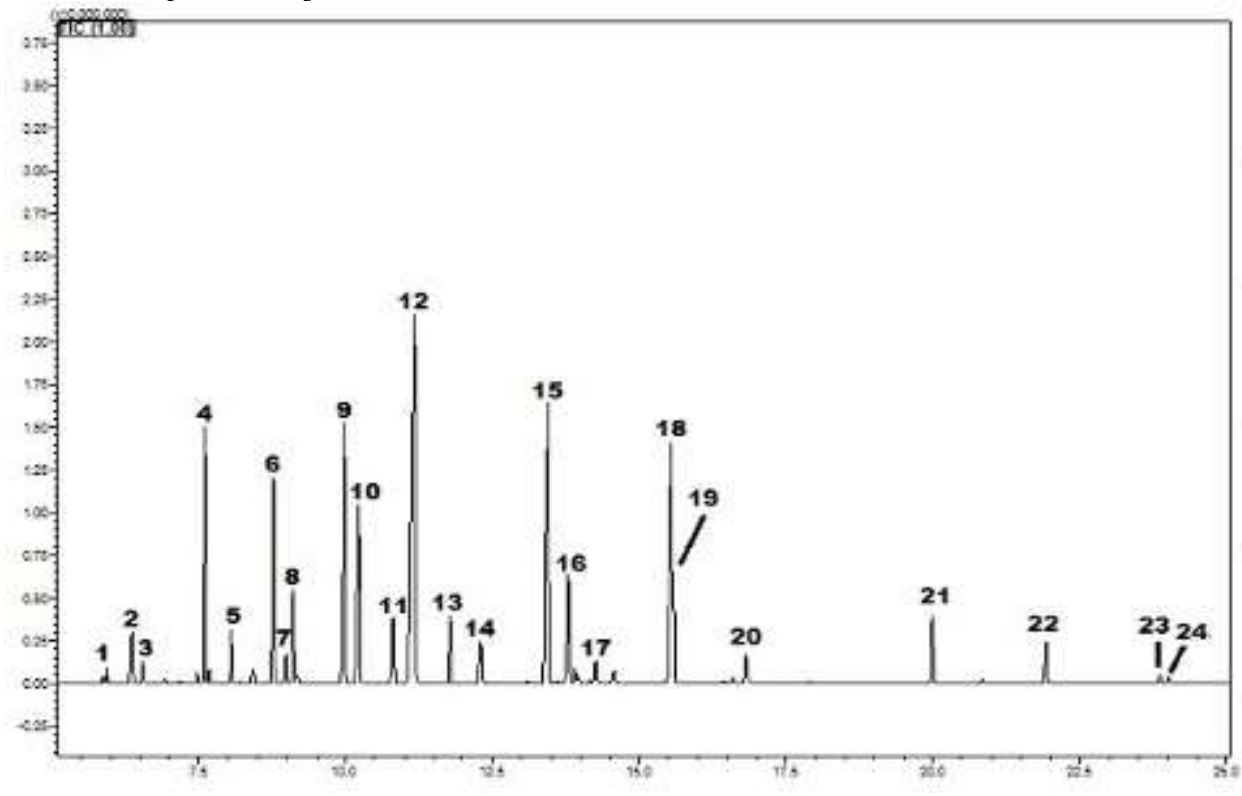

Fonte: Autores.

Conforme os resultados expressos na Tabela 1, o óleo essencial de MARJ manteve a viabilidade celular em ambas as linhagens, neoplásica (B16F10) e não-neoplásica (MDBK). Não houve alteração de fluidez (F) em células de melanoma, enquanto MARJ a $0,5 \mathrm{mg} / \mathrm{mL}$ e $1 \mathrm{mg} / \mathrm{mL}$ reduziu F nas células não-neoplásicas. Embora alguns componentes terpênicos de MARJ sejam capazes de aumentar a F por interagirem com pontes de hidrogênio na bicamada lipídica, com risco de morte celular (Mendanha et al., 2013), inclusive sobre membrana plasmática de células de hepatoma (Erdogan \& Ozcan, 2017), não foi observada alteração na membrana plasmática das células de melanoma no presente estudo. Também não foram observados prejuízos à viabilidade celular em decorrência da redução da fluidez nas membranas celulares na linhagem MDBK (com MARJ a $0,5 \mathrm{mg} / \mathrm{mL}$ e $1 \mathrm{mg} / \mathrm{mL})$. 
Tabela 1 - Parâmetros celulares avaliados para estudo de mecanismo de ação de diferentes concentrações de óleo essencial de Origanum majorana L. em linhagens celulares de melanoma (B16F10) e de não-neoplásica (MDBK) por citometria de fluxo.

\begin{tabular}{|c|c|c|c|c|c|}
\hline \multirow{2}{*}{ Parâmetros } & \multirow{2}{*}{$\begin{array}{l}\text { Linhagem } \\
\text { celular }\end{array}$} & \multicolumn{4}{|c|}{ Origanum majorana L. (mg/mL) } \\
\hline & & 0 & 0,25 & 0,5 & 1 \\
\hline \multirow[t]{2}{*}{$\mathbf{F}(\%)$} & MDBK & $31,25^{\mathrm{A}} \pm 7,14$ & $36,62^{\mathrm{A}} \pm 24,11$ & $10,95^{\mathrm{B}} \pm 2,82$ & $12,12^{\mathrm{B}} \pm 1,94$ \\
\hline & B16F10 & $21,70^{\mathrm{A}} \pm 22,14$ & $35,45^{\mathrm{A}} \pm 34,48$ & $31,77^{\mathrm{A}} \pm 24,46$ & $29,65^{\mathrm{A}} \pm 19,63$ \\
\hline \multirow[t]{2}{*}{ ERO } & MDBK & $8637,8^{\mathrm{A}} \pm 5683,4$ & $1521,5^{\mathrm{B}} \pm 548,47$ & $751,2^{\mathrm{B}} \pm 659,41$ & $315,5^{\mathrm{B}} \pm 96,97$ \\
\hline & B16F10 & $10546^{\mathrm{A}} \pm 6072,1$ & $3138,5^{\mathrm{B}} \pm 258,9$ & $2616,5^{\mathrm{B}} \pm 544,03$ & $2413,3^{\mathrm{B}} \pm 850,25$ \\
\hline \multirow[t]{2}{*}{ LPO (\%) } & MDBK & $53,13^{\mathrm{A}} \pm 3,52$ & $34,94^{\mathrm{B}} \pm 3,56$ & $20,87^{\mathrm{C}} \pm 2,16$ & $36,16^{\mathrm{B}} \pm 1,68$ \\
\hline & B16F10 & $50,18^{\mathrm{A}} \pm 8,08$ & $36,91^{\mathrm{AB}} \pm 12,07$ & $28,93^{\mathrm{B}} \pm 2,75$ & $42,25^{\mathrm{AB}} \pm 23,28$ \\
\hline \multirow[t]{2}{*}{ IFD } & MDBK & $0,28^{\mathrm{A}} \pm 0,21$ & $0,20^{\mathrm{A}} \pm 0,25$ & $0,41^{\mathrm{A}} \pm 0,24$ & $0,43^{\mathrm{A}} \pm 0,21$ \\
\hline & B16F10 & $0,23^{\mathrm{A}} \pm 0,03$ & $0,22^{\mathrm{A}} \pm 25,21$ & $0,23^{\mathrm{A}} \pm 9,82$ & $0,20^{\mathrm{A}} \pm 0,05$ \\
\hline \multirow[t]{2}{*}{ Apoptose } & MDBK & $0,12^{\mathrm{A}} \pm 0,19$ & $0,07^{\mathrm{A}} \pm 0,15$ & $0,17^{\mathrm{A}} \pm 0,22$ & $0,22^{\mathrm{A}} \pm 0,26$ \\
\hline & B16F10 & $4,07^{\mathrm{A}} \pm 4,87$ & $4,32^{\mathrm{A}} \pm 7,52$ & $6,10^{\mathrm{A}} \pm 7,95$ & $14,02^{\mathrm{A}} \pm 16,4$ \\
\hline \multirow[t]{2}{*}{ Necrose $(\%)$} & MDBK & $14,15^{\mathrm{AB}} \pm 11,30$ & $18,05^{\mathrm{A}} \pm 10,05$ & $8,1^{\mathrm{AB}} \pm 4,76$ & $4,7^{\mathrm{B}} \pm 1,65$ \\
\hline & B16F10 & $29,30^{\mathrm{A}} \pm 27,87$ & $35,65^{\mathrm{A}} \pm 25,37$ & $40,45^{\mathrm{A}} \pm 23,77$ & $24,30^{\mathrm{A}} \pm 27,87$ \\
\hline \multirow[t]{2}{*}{$\begin{array}{l}\text { Viabilidade } \\
(\%)\end{array}$} & MDBK & $85,72^{\mathrm{AB}} \pm 11,16$ & $81,87^{\mathrm{B}} \pm 9,96$ & $91,72^{\mathrm{AB}} \pm 4,56$ & $95,07^{\mathrm{A}} \pm 1,42$ \\
\hline & B16F10 & $66,62^{\mathrm{A}} \pm 26,31$ & $60,02^{\mathrm{A}} \pm 25,21$ & $53,45^{\mathrm{A}} \pm 19,79$ & $61,67^{\mathrm{A}} \pm 24,92$ \\
\hline \multirow[t]{2}{*}{ PMM (\%) } & MDBK & $23,2^{\mathrm{B}} \pm 4,18$ & $40,15^{\mathrm{A}} \pm 4,18$ & $23,54^{\mathrm{B}} \pm 2,89$ & $23,2^{\mathrm{B}} \pm 3,74$ \\
\hline & B16F10 & $75,67^{\mathrm{AB}} \pm 50,05$ & $67,08^{\mathrm{B}} \pm 56,68$ & $62,38^{\mathrm{B}} \pm 71,47$ & $142,40^{\mathrm{A}} \pm 54,64$ \\
\hline \multicolumn{6}{|l|}{ Ciclo Celular } \\
\hline \multirow[t]{2}{*}{ G1 (\%) } & MDBK & $32,15^{\mathrm{AB}} \pm 14,77$ & $25,56^{\mathrm{B}} \pm 5,4$ & $29,42^{\mathrm{AB}} \pm 13,7$ & $43,43^{\mathrm{A}} \pm 18,66$ \\
\hline & B16F10 & $9,5^{\mathrm{A}} \pm 1,35$ & $4,33^{\mathrm{B}} \pm 0,28$ & $5,95^{\mathrm{AB}} \pm 1,37$ & $5,35^{\mathrm{AB}} \pm 1,11$ \\
\hline \multirow[t]{2}{*}{$\mathrm{S}(\%)$} & MDBK & $43,33^{\mathrm{A}} \pm 15,2$ & $14,81^{\mathrm{B}} \pm 3,6$ & $20,40^{\mathrm{B}} \pm 4,51$ & $22,12^{\mathrm{B}} \pm 7,6$ \\
\hline & B16F10 & $28,38^{\mathrm{B}} \pm 2,33$ & $84,78^{\mathrm{A}} \pm 2,9$ & $90,95^{\mathrm{A}} \pm 2,21$ & $89,23^{\mathrm{A}} \pm 0,91$ \\
\hline \multirow[t]{2}{*}{ G2 $(\%)$} & MDBK & $24,51^{\mathrm{C}} \pm 1,9$ & $59,63^{\mathrm{A}} \pm 5,11$ & $50,18^{\mathrm{AB}} \pm 17,62$ & $34,45^{\mathrm{BC}} \pm 24,8$ \\
\hline & B16F10 & $62,13^{\mathrm{A}} \pm 3,42$ & $10,9^{\mathrm{B}} \pm 2,86$ & $3,1^{\mathrm{B}} \pm 0,92$ & $5,43^{\mathrm{B}} \pm 1,72$ \\
\hline
\end{tabular}

Fonte: Autores.

A produção de ERO foi indiretamente proporcional às concentrações de MARJ, que a $1 \mathrm{mg} / \mathrm{mL}$ levou à menor porcentagem de ERO em ambas as linhagens celulares, especialmente em MDBK. De forma semelhante, a lipoperoxidação (LPO) também diminuiu nas células neoplásicas e não-neoplásicas. Quando estão em equilíbrio, as ERO são fisiologicamente formadas em pequenas quantidades a partir do metabolismo aeróbio de forma constante, sendo neutralizadas por antioxidantes enzimáticos endógenos (Ramadan et al., 2012; Soliman et al., 2016) Porém, o excesso de produção de ERO danifica as estruturas celulares, devido à oxidação que provoca nos lipídios da membrana plasmática, na molécula de DNA e em proteínas 
celulares (Soliman et al., 2016), estando envolvido na carcinogênese e na mutagênese (Abdel-Massih et al., 2010; Bayala et al., 2014).

Outra estrutura que é afetada quando há excesso de ERO é a membrana mitocondrial, que pode ter perda do seu potencial, causando danos à cadeia respiratória celular, sendo essa também uma via de indução ao processo apoptótico (Nanni et al., 2020). Tais alterações não foram observadas nos tratamentos com MARJ, havendo aumento do PMM na linhagem MDBK somente com a concentração de $0,25 \mathrm{mg} / \mathrm{mL}$, sem provocar alterações mitocondriais nas células cancerígenas. A atividade antioxidante do MARJ percebida nas estruturas celulares como mitocôndrias (PMM), membrana plasmática (F e LPO) e no DNA (IFD) de ambas as linhagens estudadas, é corroborada pelos resultados obtidos no parâmetro apoptose, que não foi alterado em nenhuma das concentrações utilizadas de MARJ. Esses resultados indicam que MARJ é incapaz de induzir a morte celular através do aumento do estresse oxidativo e de suas consequentes lesões estruturais, o que é promissor, principalmente em relação às células sadias.

O efeito citoprotetor de MARJ foi demonstrado em rins afetados por danos tóxicos de cisplatina (Soliman et al., 2016) e na pele, fígado e baço de ratos experimentalmente infectados com patógeno fúngico (Waller et al., 2019), sem causar prejuízo na terapia principal. Esses resultados estão de acordo com o presente estudo e mostram a possibilidade do uso de MARJ na proteção de diferentes tecidos orgânicos, de forma adjuvante ao tratamento convencional, visando reduzir os efeitos adversos.

A principal diferença de atividade de MARJ entre as linhagens utilizadas observada nesse estudo, está no ciclo celular. Enquanto nas células MDBK houve um aumento na porcentagem de células tratadas com MARJ (concentrações de $0,25 \mathrm{mg} / \mathrm{mL}$ e $0,5 \mathrm{mg} / \mathrm{mL}$ ) que chegaram ao final do processo de divisão (fase G2), nas células de melanoma murino houve redução em G2 (concentraç̃oes de $0,25 \mathrm{mg} / \mathrm{mL}, 0,5 \mathrm{mg} / \mathrm{mL}$ e $1 \mathrm{mg} / \mathrm{mL}$ ). Esses resultados indicam que MARJ exerceu atividade citostática sobre as células de melanoma, uma vez que foi capaz de frear a divisão celular propriamente dita (fase G2), impedindo, assim, a proliferação celular maligna. O mecanismo de ação para a ocorrência desse tipo de atividade envolve estruturas específicas das células neoplásicas, uma vez que esse efeito citostático não foi observado nas células MDBK.

O ciclo celular divide-se nas fases G1, S e G2 cuja progressão e, consequentemente, a divisão celular, é dependente da atuação de genes específicos, que coordenam a atividade de ciclinas e de quinases dependentes de ciclinas (Cdk), as quais só atuam em associação, formando pares regulatórios, próprios de cada fase (Zuccari et al., 2016). Nesse contexto, o mecanismo de ação do MARJ pode estar relacionado à inibição da expressão de genes responsáveis pelo início da mitose, como p21, p27 e da CDK1 e dos processos enzimáticos subsequentes (Nanni et al., 2020). Semelhantemente à ação de MARJ sobre os eventos regulatórios das fases S e G2 do ciclo celular, outras formulações terapêuticas também inibiram seletivamente a multiplicação celular neoplásica, atuando em sítios como a tirosina quinase WEE1, enzima aurora quinase A (AURK A) e complexo p38/MK2 (Xu \& Mcarthur, 2016).

O composto 4-terpineol, também presente em Melaleuca alternifolia freou o ciclo celular em linhagens de melanoma e de mesotelioma humanos e promoveu necrose (Greay et al., 2010). Esse composto é prevalente em MARJ, corroborando com os achados de Greay e colaboradores (2010) em relação ao ciclo celular, embora não tenha promovido necrose. Esse fato pode estar relacionado às diferentes atividades exercidas pelo composto químico isolado e pelo óleo essencial, onde pode haver influência do sinergismo entre os seus componentes (Hajlaoui et al., 2016).

O etoposídeo, fármaco empregado na terapêutica do câncer em humanos, cujo mecanismo de ação compreende a indução do bloqueio pré-mitótico, no final da fase $\mathrm{S}$ ou no início da fase $\mathrm{G} 2$, através da sua ligação com a enzima topoisomerase II, bloqueando a função enzimática de reparar as fitas de DNA previamente separadas no processo de replicação (Brandão et al., 2010).

Assim como foi observado nas células de melanoma murino para o óleo essencial, o extrato etanólico de $O$. majorana 
L. também inibiu a proliferação celular e a formação de metástases de células do câncer de mama e pró-apoptótica de leucemia (Abdel-Massih et al, 2010; Dhaheri et al., 2013), mostrando que diferentes extratos dessa planta são antitumorais. No entanto, o óleo de MARJ não induziu à apoptose em melanoma, diferentemente do extrato etanólico (Abdel-Massih et al., 2010; Dhadheri et al., 2014), possivelmente pela diversidade de componentes químicos presentes nos extratos polares e apolares.

\section{Conclusão}

A atividade antiproliferativa seletiva sobre as células de melanoma demonstrou que o mecanismo de ação de MARJ tem como alvo o ciclo celular. Esse promissor resultado traz a necessidade de estudos futuros para elucidar, especificamente, qual é o ponto da divisão celular em que MARJ atua, visando sua aplicação na terapia antineoplásica. Portanto, sugere-se estudos futuros acerca do exato ponto da fase celular de células neoplásicas em que MARJ atua como inibidor da divisão celular, a fim de melhor compreender sua ação como antineoplásico. Outra observação promissora consiste na atividade antioxidante em ambas as linhagens celulares utilizadas, que possibilita ainda o uso de MARJ como adjuvante ao tratamento quimioterápico ou ainda na prevenção da carcinogênese, já que é capaz de proteger as células de danos oxidativos, mesmo em baixas concentrações.

\section{Referências}

Abdel-Massih, R. M., Fares, R., Bazzi, S., El-Chami, N., \& Baydoun, E. (2010). The apopitotic and anti-proliferative activity of Origanum majorana extracts on human leukemic cell line. Leukemia Research, 34, 1052-1056.

American Cancer Society. Cancer facts \& figures 2021 - Skin. https:/www.cancer.org/research/cancer-facts-statistics/all-cancer-facts-figures/cancer-factsfigures-2021.html

Arathi, B. P, Sowmya, P. R., Kuriakose, G. C., Vijay, K., Baskaran, V., Jayabaskaran, C., \& Lakshminarayana, R. (2016). Enhanced cytotoxic and apoptosis inducing activity of lycopene oxidation products in different cancer cell lines. Food and Chemical Toxicology, 97, $265-276$.

Balusamy, S. R., Perumalsamy, H., Huq, M. A., \& Balasubramanian, B. (2018). Anti-proliferative activity of Origanum vulgare inhibited lipogenesis and induced mitochondrial mediated apoptosis in human stomach cancer cell lines. Biomedicine and pharmacotherapy, 108, $1835-1844$.

Bayala, B., Bassole, I. H. N., Scifo, R., Gnoula, C., Morel, L., Lobaccaro, J. M. A., \& Simpore, J. (2014). Anticancer activity of essential oils and their chemical components - a review. American Journal of Cancer Research, 4(6), 591-607.

Brandão, H. N., David, J. P., Couto, R. D., Nascimento, J. A. P., \& David, J. M. (2010). Química e farmacologia de quimioterápicos antineoplásicos derivados de plantas. Química Nova, 33(1), 1359 -1369.

Brasil. (1988). Farmacopéia Brasileira - Volume 1. Agência Nacional de Vigilância Sanitária.

Bray, F., Ferlay, J., Soerjomataram, I., Siegel, R. L., Torre, L. A., \& Jemal, (2018). A. Global cancer statistics 2018: GLOBOCAN estimates of incidence and mortality worldwide for 36 cancers in 185 countries. CA: A Cancer Journal for Clinicians, 68(6), 394-424.

Del Ré, P. V. \& Jorge, N. (2012). Especiarias como antioxidantes naturais: aplicações em alimentos e implicação na saúde. Revista Brasileira de Plantas Medicinais, 14(2), 389-399.

Dhaheri, Y. A., Attoub, S., Arafat, K., Abuqamar, S., Viallet, J., Saleh, A., Agha, H. A., Eid, A., \& Iratni, R. (2013). Anti-Metastatic and Anti-Tumor Growth Effects of Origanum majorana on Highly Metastatic Human Breast Cancer Cells: Inhibition of NFkB Signaling and Reduction of Nitric Oxide Production. PLoS One, 8(7).

Domínguez-Rebolledo, A. E., Martínez-Pastor, F., Bisbal, A. F., Ros-Santaella, J. L, García-Álvarez, O., Maroto-Morales, A., Soler, A. J., Garde, J. J., \& Fernández-Santos, M. R. (2010). Response of thawed epididymal red deer spermatozoa to increasing concentrations of hydrogenperoxide, and importance of individual male variability. Reproduction in Domestic Animals, 46, 393-403.

El-Ashmawy, I. M., Saleh, A., \& Salama, O. M. (2007). Effects of Marjoram Volatile Oil and Grape Seed Extract on Ethanol Toxicity in Male Rats. Basic \& Clinical Pharmacology \& Toxicology, 101, 320-327.

Erdogan. A. \& Ozkan, A. (2017). Investigatıon of Antioxıdative, Cytotoxic, Membrane-Damaging and Membrane-Protective Effects of the Essentıal Oil of Origanum majorana and its Oxygenated Monoterpene Component Linalool in Human-Derived Hep G2 Cell Line. Iranian Journal of Pharmaceutical Research, 16, 24-34.

Evenson, D. \& Jost, L. (1994). Sperm chromatin structure assay: DNA denaturability. Methods in Cell Biology, 42, 159-176.

Fitzmaurice, C., Allen, C., \& Barber, R. M. (2018). Global, Regional, and National Cancer Incidence,Mortality, Years of Life Lost, Years Lived With Disability, and Disability-Adjusted Life-years for 32 Cancer Groups, 1990 to 2015: A Systematic Analysis for the Global Burden of Disease Study. Journal of American Medical Association Oncology, 3(4), 524-548. 
Goldschmidt, M. H., \& Hendrick, M. J. (2002). Tumors of the Skin and Soft Tissues. In: Meuten, D.J. Tumors in Domestic Animals. 4 ed. Iowa: Iowa State Press.

Greay, S. J., Ireland, D. J., Kissick, H. T., Levy, A., Beilharz, M. W., Riley, T. V., \& Carson, C. F. (2010). Induction of necrosis and cell cycle arrest in murine cancer cell lines by Melaleuca alternifolia (tea tree) oil and terpinen-4-ol. Cancer Chemotherapy Pharmacology, 65, 877-888.

Habibi, E., Shokrzadeh, M., Chabra, A., Naghshvar, F., Keshavarz-Maleki, R., \& Ahmadi, A. (2014). Protective effects of Origanum vulgare ethanol extract against cyclophosphamide-induced liver toxicity in mice. Pharmaceutical Biology, 53(1), 1-6.

Hajlaoui, H., Mighri, H., Aouni, M., Gharsallah, N., \& Kadri, A. (2016). Chemical composition and in vitro evaluation of antioxidant, antimicrobial, cytotoxicity and anti-acetylcholinesterase properties of Tunisian Origanum majorana L. essential oil. Microbial Pathogenesis, 95, 86-94.

Instituto Nacional do Câncer - Estimativa 2018: incidência de câncer no Brasil. (2017). Instituto Nacional de Câncer José Alencar Gomes da Silva. Coordenação de Prevenção e Vigilância. Rio de Janeiro: INCA.

Khan, M. S. A., Ahmad, I., \& Cameotra, S. S. (2014). Carum copticum and Thymus vulgaris oils inhibit virulence in Trichophyton rubrum and Aspergillus spp. Brazilian Journal of Microbiology, 45(2), 523-531.

Mendanha, S. A., Moura, S. S., Anjos, J. L. V., Valadares, M. C., \& Alonso, A. (2013). Toxicity of terpenes on fibroblast cells compared to their hemolytic potential and increase in erythrocyte membrane fluidity. Toxicology in Vitro, 27, 323-329.

Nanni, V., Di Marco, G., Sachetti, G., Canini, A., \& Gismondi, A. (2020). Oregano Phytocomplex Induces Programmed Cell Death in Melanoma Lines via Mitochondria and DNA Damage. Foods, 9, 1-27.

Petrunkina, A. M., \& Harrison, R. A. (2013) Fluorescence technologies for evaluating male gamete (dys) function. Reproduction in Domestic Animals, 48, 1124.

Pereira A. S., Shitsuka, D. M., Parreira, F. J. \& Sitsuka, R. (2018). Metodologia da pesquisa científica. UFSM.

Ramadan, G., El-Beih, N. M., \& Zahra, M. M. (2012). Egyptian sweet marjoram leaves protect against genotoxicity, immunosuppression and other complications induced by cyclophosphamide in albino rats. British Journal of Nutrition, 108, 1059-1068.

Sharma, M., Agrawal, S. K., Sharma, P. R., Chadha, B. S., Khosla, M. K., \& Saxena, A. K. (2010). Cytotoxic and apoptotic activity of essential oil from Ocimum viride towards COLO 205 cells. Food and Chemical Toxicology, 48, 336-344.

Silva, C. S. 2016. Estudo retrospectivo de melanomas cutâneos caninos e determinação da atividade citotóxica de produtos vegetais frente a células neoplásicas (B16F10) e não neoplásicas (MDBK). 2016. 88f. Dissertação (Mestrado) - Programa de Pós-Graduação em Veterinária - Universidade Federal de Pelotas - Pelotas.

Silva, C. S., Guim, T. N., Fernandes, C. G., Barboza, D. V., \& Cleff, M. B. Estudo retrospectivo de melanomas cutâneos em cães. (2017). Clínica Veterinária, 22(126), 52-60.

Silva, E. C. B., Cajueiro, J. F. P., Silva, S. V., Soares, V. P., \& Guerra, M. M. P. (2012). Effect of antioxidants resveratrol and quercetin on in vitro evaluation of frozen ram sperm. Theriongelonogy, $77,1722-1726$.

Soliman, A. M., Desouky, S., Marzouk, M., \& Sayed, A. A. (2016). Origanum majorana Attenuates Nephrotoxicity of Cisplatin Anticancer Drug through Ameliorating Oxidative Stress. Nutrients, 8(264), 1-9.

Tatman, D., \& Mo, H. (2002). Volatile isoprenoid constituents of fruits, vegetables and herbs cumulatively suppress the proliferation of murine B16 melanoma and human HL-60 leukemia cells. Cancer Lettters, 175, 129-139.

Waller, S. B., Cleff, M. B., Mattos, C. B., Silva, C. C., Giordani, C., Lana, D. F. D., Fuentefria, A. M., Freitag, R. A., Sallis, E. S. V., Mello, J. R. B., Faria, R. O., \& Meireles, M. C. A. (2019). In vivo protection of the marjoram (Origanum majorana Linn.) essential oil in the cutaneous sporotrichosis by Sporothrix brasiliensis. Natural Product and Research, 17, 1-5.

Weyden, L., Brenn, T., Patton, E. E., Wood, G. A., \& Adams, D. J. (2020). Spontaneously occurring melanoma in animals and their relevance to human melanoma. The Journal of Pathology, 252(1), 4-21.

Xu, W. \& Macarthur, G. (2016). Cell Cycle Regulation and Melanoma. Current Oncology Reports, 18, 1-12.

Zuccari, D. A. P. C., Jardim-Perassi, B. V., Lopes, J. R., Colombo, J., \& Silva, C. L. (2016). Biologia do Câncer. In: Daleck, C. R., De Nardi, A. B. Oncologia em Cães e Gatos. Roca. 